\title{
Dos banhos de mar aos esportes nas zonas de praia e no mar
}

\author{
From sea-bathing to sports in beach and sea areas
}

\author{
Alexandre Queiroz Pereira ${ }^{1}$ \\ Eustógio Wandeley Correia Dantas ${ }^{2}$
}

\begin{abstract}
Resumo
Dos banhos de mar aos esportes nas zonas de praia e no mar objetiva apreender a valorização sociocultural dos espaços litorâneos nos trópicos. Pautados, inicialmente, em práticas marítimas modernas mais convencionais como os Banhos de mar e os Banhos de Sol, respectivamente de caráter terapêutico e recreativo, a valorização converge, na contemporaneidade, para práticas de caráter esportivo, aquáticas e náuticas, com ênfase maior dada ao kitesurf. Metodologicamente, utiliza-se de banco de dados e trabalhos de campo realizados pelo Grupo de Pesquisa da Urbanização Litorânea e Lazer, do Laboratório de Planejamento Urbano e Regional da Universidade Federal do Ceará. A compreensão é multescalar e os pressupostos teóricos associam-se a geografia urbana e dos lazeres. Como desdobramentos principais, apontam-se, de um lado, os esportes náuticos, sobretudo o Kitesurfe, como a mais nova variável de incorporação e modernização da praia nos trópicos e, de outro, a consistituição de fenômeno mundial materializado em diversos contextos, como o do Nordeste brasileiro e, mais especificamente, do litoral cearense.
\end{abstract}

Palavras-chave: urbanização; kitesurfe; trópicos; esportes náuticos; Nordeste do Brasil.

\begin{abstract}
From sea-bathing to sports in the beach and sea areas aims to understand the sociocultural appreciation of coastal spaces in the tropics, initially based on more conventional modern maritime practices such as Sea Baths and Sun Bathing, of a therapeutic and recreational character, respectively, and to converge, in modern times on the practices of a sporting, aquatic and nautical nature, with greater emphasis given to kitesurfing. Methodologically, the study uses a database and fieldwork carried out by the Coastal and Leisure Urbanization Research Group of the Urban and Regional Planning Laboratory of the Federal University of Ceará. The understanding is multiscalar and the theoretical assumptions are associated with urban geography and leisure. The main dispositions are, on the one hand, nautical sports, especially kitesurfing, which is the newest variable for the incorporation and modernization of the beach in the tropics and, on the other hand, the constitution of a global phenomenon materialized
\end{abstract}

\footnotetext{
${ }^{1}$ Universidade de Federal do Ceará, Fortaleza, Ceará, Brasil. aqpereira@ufc.br.

2 Universidade de Federal do Ceará, Fortaleza, Ceará, Brasil. ewcdantas@ufc.br.

Artigo recebido em: 14/02/2019. Aceito para publicação em: 29/04/2019.
} 
significantly in different contexts, such as the Northeast of Brazil and, more specifically, the coast of Ceará.

Keywords: urbanization; kitesurfing; tropics; nautical sports; Northeast of Brazil.

\section{Introdução}

Da apreensão da praia no Ocidente (especificamente a Europa Ocidental) como território "do medo" (DELUMEAU, 1978) e "do vazio" (CORBIN, 1988), vislumbra-se, no final do século XVIII início do século XIX, sua configuração em lócus estratégico de sociabilidade, associado ao delineamento de práticas terapêuticas e de lazer empreendidas, à época, por suas elites. De início, a nobreza ao incorporar os Banhos de Mar assentados nas estações balneárias. $\mathrm{Na}$ sequência, a burguesia sequiosa, pura e simplesmente, em usufruir e, consequentemente, reproduzir fidedignamente o estilo de vida concebido e implementado pelos nobres (Civilisation des Moeurs) (ELIAS, 1973).

Dado seu caráter elitista associado a outros limites impostos à época, principalmente no domínio dos transportes, a circunscrição destas práticas tarda em ultrapassar o continente europeu, se constituindo o Mediterrâneo, dado suas peculiaridades climáticas (temperaturas amenas se comparadas ao Norte da Europa), no ponto de efervescência maior da ambiência característica deste efeito de moda (CORBIN, 1988; URBAIN, 1996). Do posto, suplantar a fronteira indicada demandava tempo (dezenas de anos) e se efetivou a partir de dois vieses: dos "Banhos de Mar" e do "Bem Respirar". No primeiro domínio, as elites formadas no "Novo Mundo" (Continente Americano) reproduzem as mesmas práticas implementadas por seus pares do Velho Mundo. A título de exemplo, a elite americana na Florida (BOYER, 1996) e a família Real e sua corte, estabelecida na capital do Brasil (Rio de Janeiro) (LINHARES, 1992; COSTA, 2013). No segundo domínio, da incorporação da ambiência litorânea (principalmente das ilhas), aos tratamentos terapêuticos, não os Banhos de Mar mas a ideia do "Bem 
Respirar", balizada na teoria de Lavoisier (CORBIN, 1988), a justificar incursão de número significativo de membros da elite europeia nos Trópicos.

A vitalidade e força de lógica de valorização das praias se mantem até nossos dias, implicando em processo de atualização constante, a referendar popularização dos gostos pelo mar e pelo marítimo na perspectiva social (efeito de massa) e concomitantemente em escala mundial. $\mathrm{Na}$ contemporaneidade, final do século XX e início do século XXI, novos usuários surgem nas zonas de praia, complexificando a paisagem urbana no exercício de práticas a conviverem com as de caráter eminentemente terapêutico (ainda praticadas mas não de forma hegemônica) e recreativo (hegemônicas). Especificamente práticas marítimas modernas de caráter esportivo (náutico e aquático), idealizadas em novo padrão estético, assentado não mais no ideário de homens saudáveis (Banhos de Mar) ou esbeltos e bronzeados (Banhos de Sol), mas daqueles a dispor de um corpo atlético e a se nutrir do ideal da interação do praticante com a natureza, no intitulado de Esportes de Aventura, "Sport de Nature" na acepção francesa (AUDINET; GUIBERT; SEBILEAU, 2017).

O delineamento de práticas esportivas na praia se justifica no entendimento da mesma como teatro social, espaço de inovações, lócus onde diferentes atores interagem, constroem e reconstroem sociabilidades, produzem, inclusive, espaços públicos direcionado à festa e ao lazer (URBAIN, 1996; RIEUCAU; LAGEISTE, 2008).

As citadas práticas se efetivam em centros espalhados no mundo, derivadas da modernização dos lugares/praias e adaptação de práticas desenvolvidas em outras ambiências e, agora, reestruturadas para a representativa da beira-mar. Tratam-se de práticas esportivas criadas e/ou adaptadas para a praia e para o mar (surfe, windsurf, beach soccer, voleibal de praia, kitesurf, etc) e novos empreendimentos a elas associados (Balneários, Resorts, Condoresorts, Parques aquáticos...). 
Os países tropicais com costas extensas, praias arenosas, quentes e ventiladas, apresentam-se como um dos protagonistas. Dantas (2016) enfatiza a efervescência destas transformações com evidência para a costa da região nordeste do Brasil. O intuído é organizar trechos do litoral nordestino em função do que chamam genericamente de atividades turísticas. Buscam-se investimentos privados para construção de redes de hotéis e/ou empreendimentos complexos também de caráter imobiliário, assim como, intenta-se a ampliação do número de turistas nestes lugares. Resultam-se, desta maneira, trechos turistificados do litoral brasileiro e, também, usufruídos pelas populações locais.

A visitação destes espaços, cidade e vilarejos, dar-se, mormente, à aproximação contínua a sua condição marítima. Evidencia-se o objetivo central ao que se propõe compreender este escrito. Essa incorporação é renovada, em tese, pela promoção dos esportes náuticos e de praia e, simultânea e, por vezes, articuladamente, a organização de festejos e/ou festivais anuais. A pretensão é demonstrar fenômeno mundial que se realiza em diversos contextos, como o do Nordeste brasileiro e mais especificamente do litoral cearense.

Em termos metodológicos, utiliza-se de banco de dados e trabalhos de campo realizados pelo Grupo de Pesquisa da Urbanização Litorânea e Lazer, do Laboratório de Planejamento Urbano e Regional da Universidade Federal do Ceará. Três são os eixos norteadores da metodologia: I) exposição do estado da arte, mormente, interpretação da bibliografia contemporânea mundial a tratar das práticas marítimas modernas, em destaque, a espanhola e francesa; II) Banco de informações, organizados a partir de fontes mundiais (associações internacionais de esportes), nacionais (Ministério do Turismo e Atlas Eólico do Brasil) e regionais (Secretaria de Turismo do Estado do Ceará); e por fim, III) Material qualitativo colhido captado durante trabalho de campo nas praias do litoral cearense, baseado na técnicas de observação, preenchimento de cardeneta de campo e entrevistas com informantes-chave. 
Pretende-se com isso, estabelecer compreensão multescalar, fortalecida por pressupostos teóricos associados à geografia urbana e dos lazeres.

A continuidade do texto é constituída de três tópicos e a conclusão. $\mathrm{O}$ primeiro, a reprodução de novas práticas marítimas, caracteriza processo de inovação e modernização das práticas marítimas de lazer, sendo, na contemporaneidade, destaque os esportes. No segundo, os esportes e lazeres na praia e no mar, traz ao debate, com evidência no mundo e também no Nordeste do Brasil, o papel dos esportes à vela na apropriação, transformação e incorporação de novos balneários marítimos. O kitesurfe no Nordesde e no Ceará é o terceiro e detalha a importância deste esporte especificamente e, também, sua relação com os lugares à beira-mar transformados por outras práticas de lazer marítimo. As conclusões, como de praxe, revelam os principais resultados da pesquisa e apontam para novas investigações.

\section{A reprodução de novas práticas marítimas}

As práticas esportivas, a exemplo das demais práticas marítimas modernas, derivam de atividades desenvolvidas pelas populações tradicionais (CORBIN, 1988). Dentre as mais antigas temos a natação e o surf. As citadas práticas foram, a exemplo das demais, ressignificadas (a partir da incorporação de novas rotinas) e aprimoradas (com o uso de novos materiais na construção dos equipamentos utilizados) no Ocidente.

No referente à natação, e exemplificando o Brasil, Lery (1994) e Thevet (1997), no início do século XVI, descrevem os indígenas como exímios nadadores, comparando-os a golfinhos. No Mediterrâneo, Corbin (1988) também exaltada esta prática, realizada nos séculos XVII e XVIII por jovens pescadores. A natação foi ressignificada no Ocidente, concomitante ao movimento de reinvenção das praias. Era praticada por homens e implicava em mostrar sua virilidade no enfrentamento do mar (CORBIN, 1988). Foi 
incorporada no Brasil, especificamente no Nordeste, a partir da realização de competições, no início do século XX, a envolver jovens do lugar, denominada "Prova Heroica". A partir dos anos de 1970 a natação abarca escalas mais amplas (internacional e nacional) e passa a compor o Triátlon a partir de 1978 (Ironman Triathlon), incorporado aos Jogos Olímpicos em Sidney (2000).

Quanto ao surfe acredita-se ser uma prática originária das Polinésias. Foi ressignificado mais recentemente, no entre guerras, tendo sua difusão se iniciado na Costa Oeste americana, principalmente praias ao sul da Califórnia (Estados Unidos das Américas). Os primeiros campeonatos (nas escalas nacionais e internacionais) foram organizados a partir de 1974.

As duas práticas esportivas acima indicadas assumem uma dimensão profissional e envolvem, indistintamente, os Países Ocidentais e os Países do Sul. De um lado, na organização e realização de campeonatos e, de outro lado, na emergência de segmento representativo de praticantes (esportistas amadores) provenientes de uma base social ampla. Por não dispor do mesmo caráter elitista das demais práticas marítimas modernas ilustradas, os praticantes (principalmente do surf), tem um perfil econômico diverso e os mesmos se articulam atualmente em rede informacional, na escala internacional, composta por adeptos em busca do lugar ideal (principalmente ambientes litorâneos com incidência de ondas) e provenientes tanto do Ocidente (GUIBERT, 2006) como de Países do Sul.

Das práticas citadas anteriormente e assentado no domínio das inovações tecnológicas (na produção de novos materiais), outras práticas esportivas são gestadas mais recentemente. Da natação à prática do mergulho (do clássico, com uso de equipamentos sofisticados, ao extremo do mergulho em apnéia). Do surf ao "Bodyboarding", resultante da confecção de novo tipo de prancha. Do surf ao "Windsurf", "Kitesurf" e "Stand up Paddle", possíveis na incorporação de novos equipamentos às pranchas diferenciadas (a vela no caso da primeira prática, a pipa na segunda e o remo na última). 
Comparadas à dinâmica imobiliária-turística, os esportes náuticos e aquáticos correspondem a práticas de menor envergadura, mas cujos desdobramentos resultam de plena articulação com cenário mundial, compondo um sistema "alternativo" com alto poder de: i. adesão às novas tecnologias informacionais; ii. adequação à infraestrutura preexistente; iii. interação com a ambiência marítima.

A alcunha de "alternativo" auxilia no entendimento de caracterização destas práticas como faz Sebileau (2017), baseado em Bordieu, ao designá-las como associadas a uma racionalidade "fora do tempo" e "fora do espaço". Em suma, diferenciada do turismo caracterizado como de massa. Nos Países do Sul se efetiva em diálogo com a natureza (da melhor época das ondas e dos bons ventos em lugares paradisíacos) e faz convergir para as zonas de praia fluxos cada vez maiores de praticantes de outros estados e de outros países. Consiste, paradoxalmente, em elemento estratégico no trato da problemática da sazonalidade (GUIBERT, 2011), ao ponto dos governos e até mesmo grandes empreendedores (principalmente indústria de produção de novos materiais, confecção e até imobiliária-turística) patrocinarem os eventos realizados (competições e campeonatos). Nestes termos se tornam, nos últimos anos, usuários fiéis do setor hoteleiro, principalmente pequenos hotéis e pousadas nas regiões metropolitanas, bem como de segundas residências, no que estudiosos espanhóis intitulam de "Turismo Residencial" (ANDREU, 2005; ALEDO, 2008; NIEVES, 2008; DEMAJOROVIC et. al., 2011; FERNÁNDEZ MUNOZ \& TIMON, 2011; TORRES BERNIER, 2013).

\section{Os esportes e lazeres na praia e no mar}

A modernização das zonas de praia, desde o final do século XIX, apresenta-se como fenômeno importante na compreensão da consolidação do gosto pelo mar e marítimo. Tal processo caracteriza-se tanto pela produção de novas construções (calçadões, piers, passarelas), instalação de 
empreendimentos de lazer (restaurantes, hotéis, parques temáticos, aquários) e na reinvenção de práticas e sua devida adaptação à praia ou ao mar. Como exemplo, Augustin (2007) descreve o caso de Lacanu-Ócean no sudoeste francês e aponta como marca das mudanças à instituição de práticas múltiplas, dentre elas e em destaque, as esportivas.

Os esportes na praia e no mar são interessantes indicadores para entender a massificação do gosto por estes ambientes. Tanto por praticadas profissionais como por amadores, o nível de organização estabelece circuito mundial de lugares à beira mar destacáveis para as práticas de distintos esportes. Os praticantes profissionais participam de eventos nacionais e internacionais produzidos por entidades confederativas e, geralmente, organizados em circuitos em praias pré-selecionadas. No caso dos praticantes, amadores há sensíveis diferenças. Primeiro, há número superior de adeptos sem vínculos à associações ou à entidades promotoras. Segundo, são maiores os números de praias selecionadas em função das condições naturais (intensidade dos ventos, altura e frequência das ondas, etc.), das materialidades construídas (infraestruturas de acesso, meios de hospedagem, etc.) e das imaterialidades (difusão de imagens dos lugares em mídias sociais, etc).

$\mathrm{Na}$ representação a seguir, estão demarcadas as sedes de etapas mundiais de diferentes modalidades: surf, kitsurf, windsurf, bodyboad, natação em águas abertas, beach soccer e vôlei de praia. Percebe-se concentração nos litorais europeus, assim como nas costas tropicais da América do Sul e da Oceania, com destaque para os litorais de Portugal, da Espanha, do Brasil e da Austrália (figura 1). Formam-se praias-arquétipos, modelos conhecidos mundialmente. Especificamente pode-se citar Pipeline (Hawaii), Gold Coast (Austrália), Saquarema e Copacabana (Rio de JaneiroBrasil), Papeete (Taiti) e Praia Grande (Portugal).

Trata-se de lugares escolhidos pelos principais praticantes destes esportes. Atletas estes que inspiram amadores a praticarem estas 
modalidades. Tais eventos esportivos impactam positivamente no fluxo de turísticas e vilegiaturistas, posto, deslocarem-se dos mais variados continentes em direção a estas e outras praias com condições ambientais semelhantes. 
Figura 1. Circuitos mundiais de esportes litorâneos.

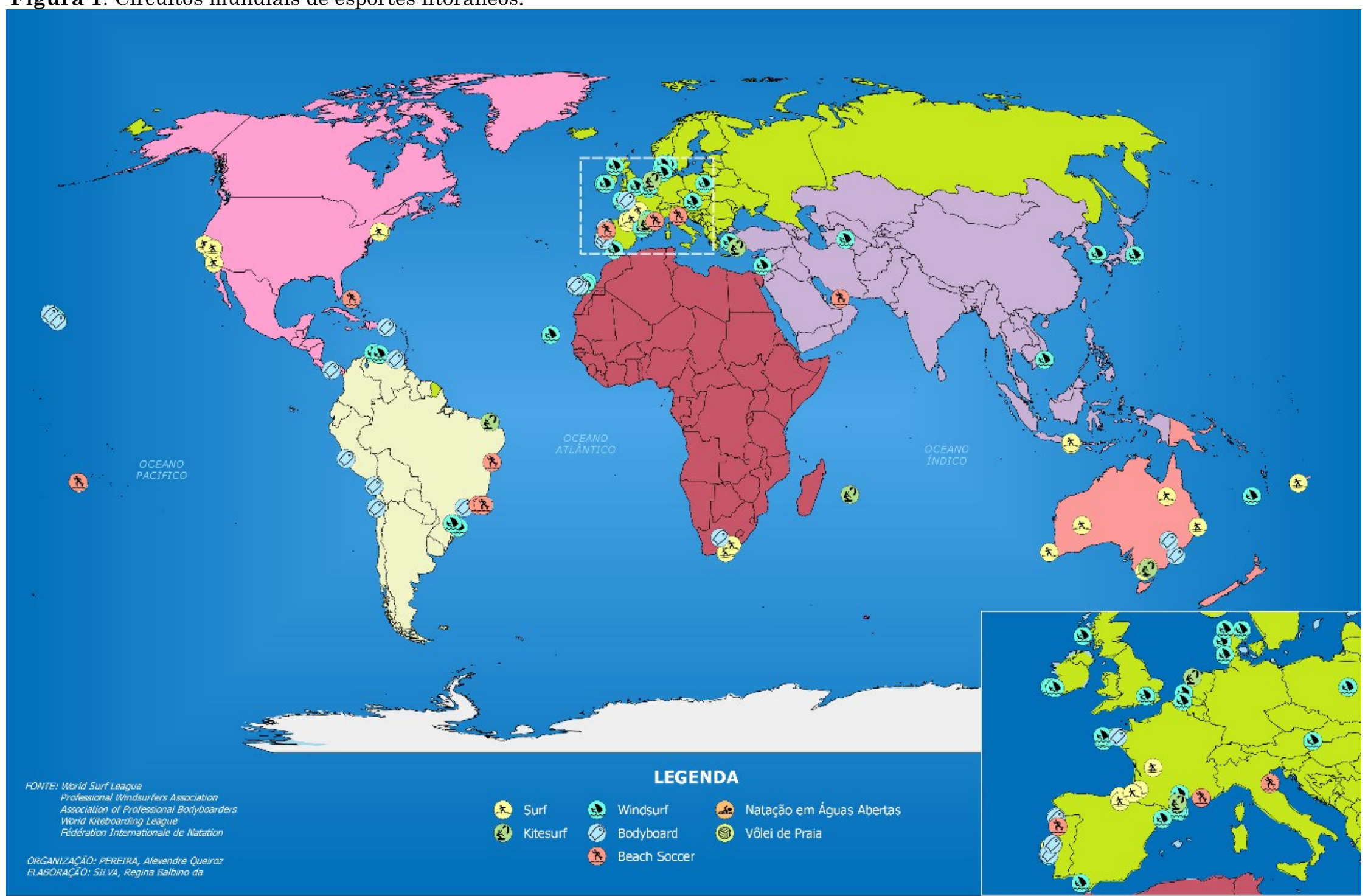

Fonte: World Surf League, Professional Windsufers Associator, Association of Professional Bodyboarders, World Kiteboarding League, Fédération Internationale de Natation e Federação Internacional de Futebol. 
Os esportes são representativos no conjunto de atividades desenvolvido nos ambientes marítimos, todavia, há hall complementar que incrementa o número e a variedade dos frequentadores das praias. Nas praias brasileiras, diariamente, observa-se outras práticas marítimas contemporâneas. Na praia se elenca o bronzeamento (Banho de Sol relatado por Urbain em 1994, no caso francês), os treinos funcionais, o frescobol, o futevôlei, entre outros. Já no mar a multiplicidade é maior e inclui atividades com uso de equipamentos motorizados, pranchas e embarcações (quadro 1).

Quadro 1. Diversidade de práticas na praia e no mar.

\begin{tabular}{|l|l|}
\hline \multicolumn{1}{|c|}{$\begin{array}{c}\text { Práticas e esportes } \\
\text { náuticos/marinhos }\end{array}$} & \multicolumn{1}{c|}{$\begin{array}{c}\text { Práticas e esportes na praia (zona } \\
\text { de areia) }\end{array}$} \\
\hline $\begin{array}{l}\text { Surf, windsurfe, kitesurf, stand up up } \\
\text { pedal, jet-ski, canoagem, remo, thiatlo, } \\
\text { banho, iatismo, pesca esportiva, } \\
\text { mergulho e caça submarina, wakeboard, } \\
\text { caiaque, esqui aquático, bodyboarding e } \\
\text { natação. }\end{array}$ & $\begin{array}{l}\text { Futebol de areia (beachsoccer), vôlei de } \\
\text { praia, futevôlei, peteca, frescobol, } \\
\text { bronzeamento e treinos funcionais. }\end{array}$ \\
\hline
\end{tabular}

Fonte: Pesquisa documental e trabalhos de campo no período 2015 a 2017.

O processo de reinvenção e produção de práticas marítimas contemporâneas se dá em virtude da abertura à mundialização das zonas de praia. São espaços de recepção de vacanciers internacionais-metropolitanos e autóctones. As praias tornam-se espaços de convergência e trocas culturais. Blondy (2013), ao estudar as práticas nas praias da Polinésia francesa, chega a interessantes conclusões a este respeito. A autora detecta, entre turistas internacionais, metropolitanos e locais, práticas diferenciadas. No caso daquelas que se concentram os autóctones, a praia é utilizada como lugar do encontro e não se estabelece necessariamente práticas de lazer. Em praias públicas da ilha constituem-se práticas híbridas, ou seja, as mundiais (os esportes, por exemplo) e as tradicionais (pesca) estabelecem convivência. O terceiro tipo constatado são as praias urbanas, também chamadas de 
ocidentais. Neste caso, quanto mais urbanizada, menos práticas tradicionais são perceptíveis.

Sem descartar as constatações de Blondy (2013), no caso das praias brasileiras turistificadas, a disseminação das práticas alcança também os alóctones. Estes praticam, reinventam atividades e incorporam-nas como possibilidade de lazer, especialmente as faixas etárias mais jovens. Além da dialética social, outras dimensões são relevantes condicionantes, neste sentido, é preciso destacar as características naturais dos ambientes praianos em termos condicionantes na atratividade de dadas praias.

Para os trópicos, em especial o litoral do nordeste do Brasil, o clima e a geomorfologia favorecem a diversidade de práticas anteriormente indicadas. A zona de espraiamento é o que popularmente se denomina praia. Tecnicamente é demarcada pela variação das marés, ou seja, “onde ocorrem os processos de fluxos (swash) e refluxo (backwash) das ondas, sendo que sua análoga morfológica é a face praial” (SILVA, G., 2006, p. 24). Em relação às ondas, a referida autora define sua origem como local ou do tipo sea, com "altura média significativa de $1,1 \mathrm{~m}$, frequência de $5 \mathrm{~s}$ e período de $15 \mathrm{~m}$ " (CLAUDINO SALES, 2007, p. 239). Predominam os sedimentos arenosos e assim são atrativos. Quando o mar "sede lugar", os estirâncios se mostram mais largos.

Inspirando-se em metodologia de Blondy (2013), estabeleceu-se observação in loco durante trabalhos de campo nas praias metropolitanas de Fortaleza-Ceará no período 2015 a 2017. Desta forma, identificou-se o trinômio localização/usuário/prática no espaço da praia. 
Figura 2. Modelo genérico de faixa de praia

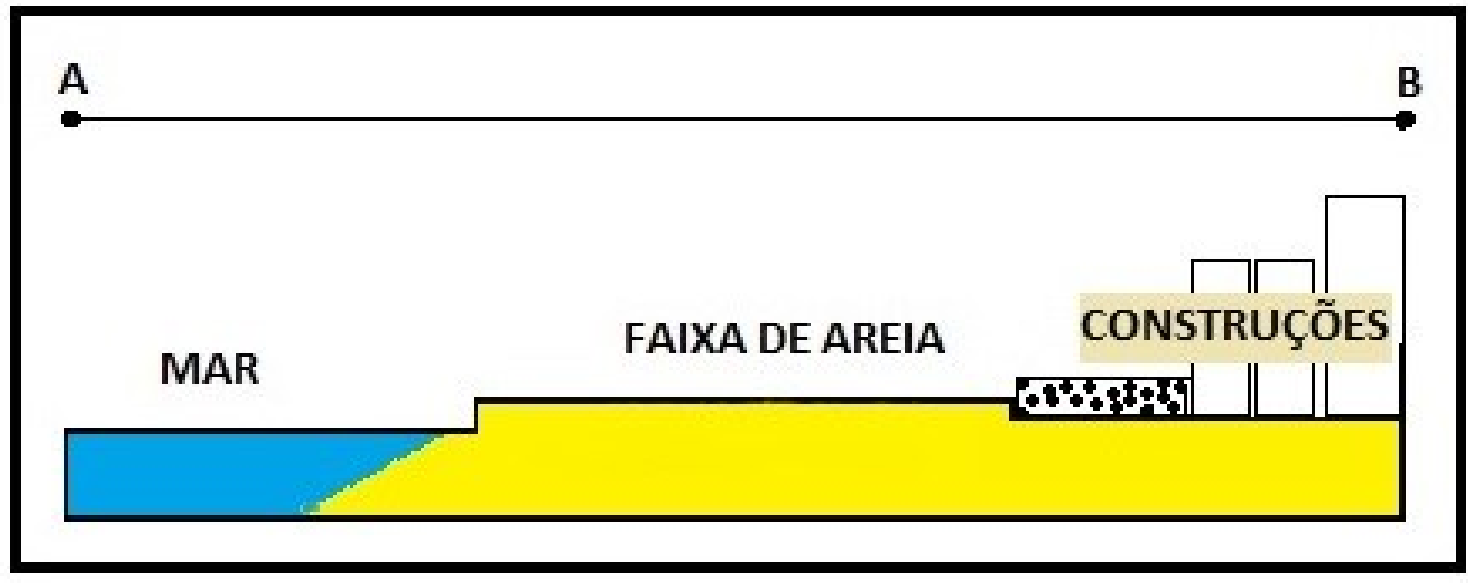

Fonte: trabalho de campo. Elaboração dos autores

A representação gráfica da figura 3 auxilia na localização das práticas. No ponto A, espaço predominantemente aquático-marítimo, onde ondas se formam destaca-se os esportes windsurf, kitesurf, surf, bodyboard e natação. A velocidade e a continuidade dos ventos contribuem sobremaneira para o desenvolvimento destes esportes. $\mathrm{Na}$ zona das águas calmas, próxima aos sedimentos de areia, o banho de mar é a principal prática marítima, capaz de reunir crianças e adultos. A terceira zona é a da areia, a faixa de praia. Nela concentram-se dezenas de práticas, dentre as predominantemente, aponta-se o banho de sol, vôlei de praia, futevôlei, beach soccer, frescobol e brincadeiras infantis. A última área apontada é da retaguarda e dos serviços que garantem a permanência dos usuários. Composta por passeios, vias a beira-mar e também restaurantes, hotéis, pousadas, resort, parques temáticos. São áreas a ampliarem as possibilidades de lazer, gastronomia e sociabilidades.

As áreas submersas, onde os usuários praticam o banho de mar, são denominas de zona de arrebentação e surfe. A primeira é caracterizada pelo processo de desestabilização e quebra das ondas, e na segunda, continuidade da primeira, ocorre a dissipação da energia das ondas. Além dessas características, a temperatura das águas marinhas se mantém confortável ao 
banho durante todo o ano, fato decorrente de fluxo de calor latente "três vezes superior ao dos mares de latitudes elevadas" (CONTI, 2010, p. 4).

As temperaturas elevadas são amenizadas pelos ventos e brisas constantes. De acordo com Moura (2008), a velocidade média normal do fluxo do ar é igual a $3,7 \mathrm{~m} / \mathrm{s}$, com picos de $4,6 \mathrm{~m} / \mathrm{s}$ registrados nos meses de setembro e outubro. As figuras 3 e 4 demonstram, para o caso brasileiro e mais, especificamente, do Nordeste, a forte e constante incidência de ventos na zona costeira. As condições climáticas associadas aos ventos permite a inserção do Nordeste brasileiro no "circuito mundial" das regiões apreciadas e visitadas por praticantes de esportes náuticos relacionados a prancha e a vela, destaque-se, o kitesurf.

Figura 3. Ventos no Brasil: direções predominantes anuais

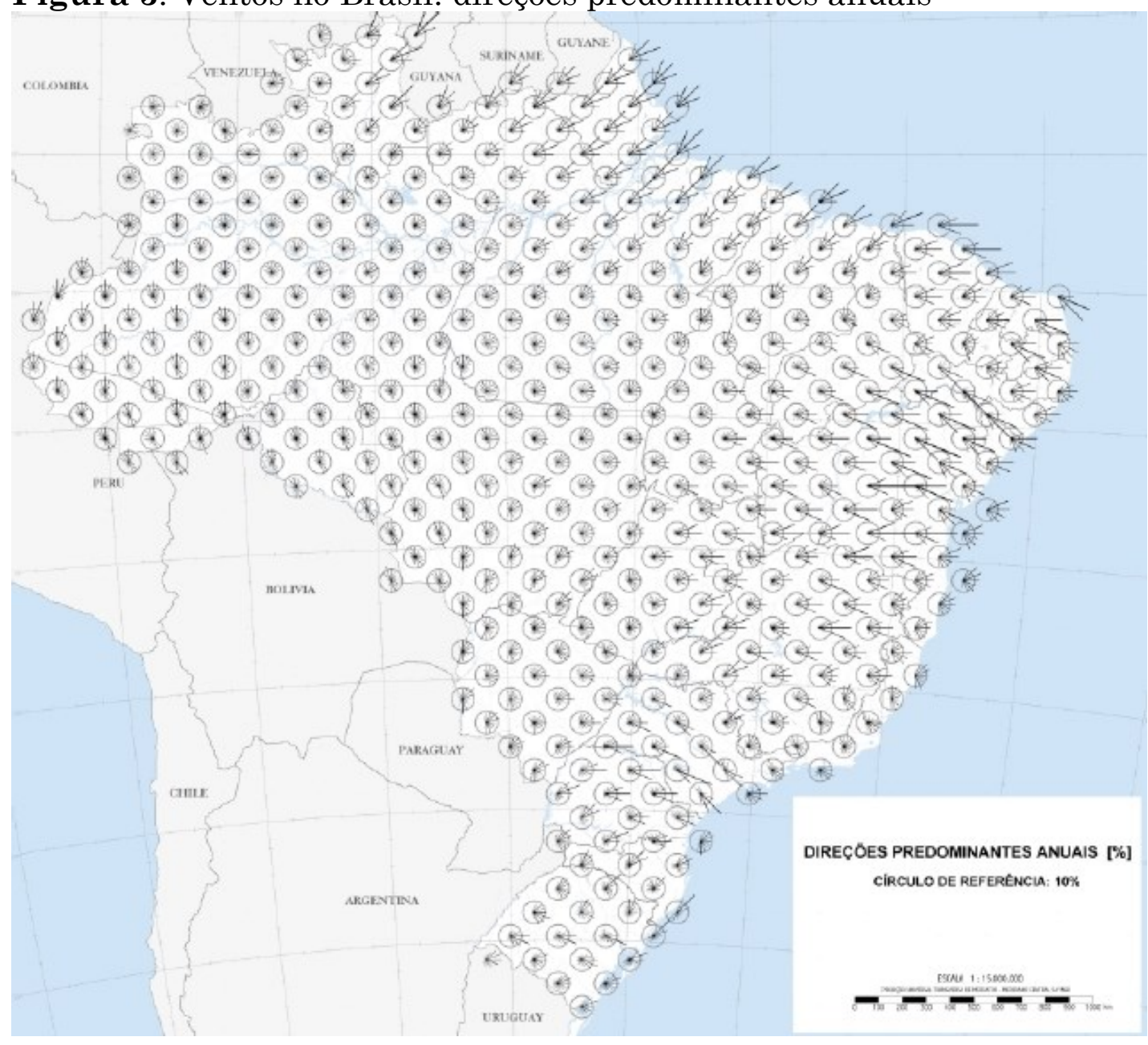

Fonte: Atlas do Potencial Eólico Brasileiro, 2001. 
Figura 4. Velocidade anual dos ventos no Nordeste do Brasil.

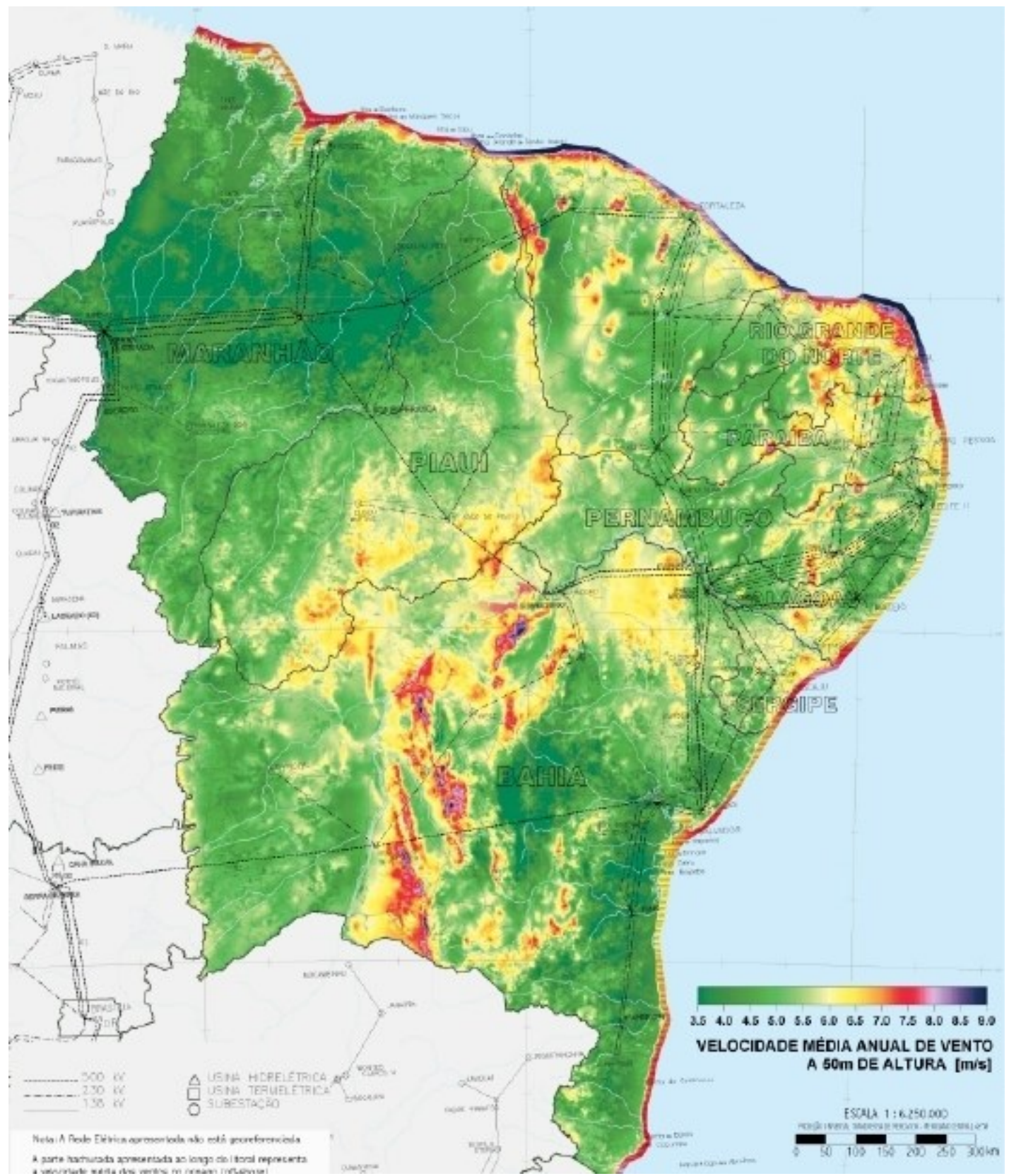

Fonte: Atlas do Potencial Eólico Brasileiro, 2001.

O kitesurfe no Nordeste e no Ceará

Pesquisadores do Grupo de Estudos Urbanização Litorânea, do Laboratório de Planejamento Urbano e Regional, utilizando-se de consulta à sites eletrônicos, à revistas especializadas e aos jornais esportivos, detectaram 
os municípios nordestinos com maior atração e recepção de praticantes de kitesurfe. Evidenciam-se 21 municípios cujas praias são privilegiadas por praticantes profissionais e amadores. Na figura 5 é possível observar lugares selecionados por kitesurfistas em todos os estados da região Nordeste do Brasil. As praias apontadas são ícones, polos, espaços de maior intensidade e predominância, fato que não exclui a possibilidade de incorporação contínua de novos trechos litorâneos.

Figura 5. Principais municípios para a prática do kitesurf no Nordeste.

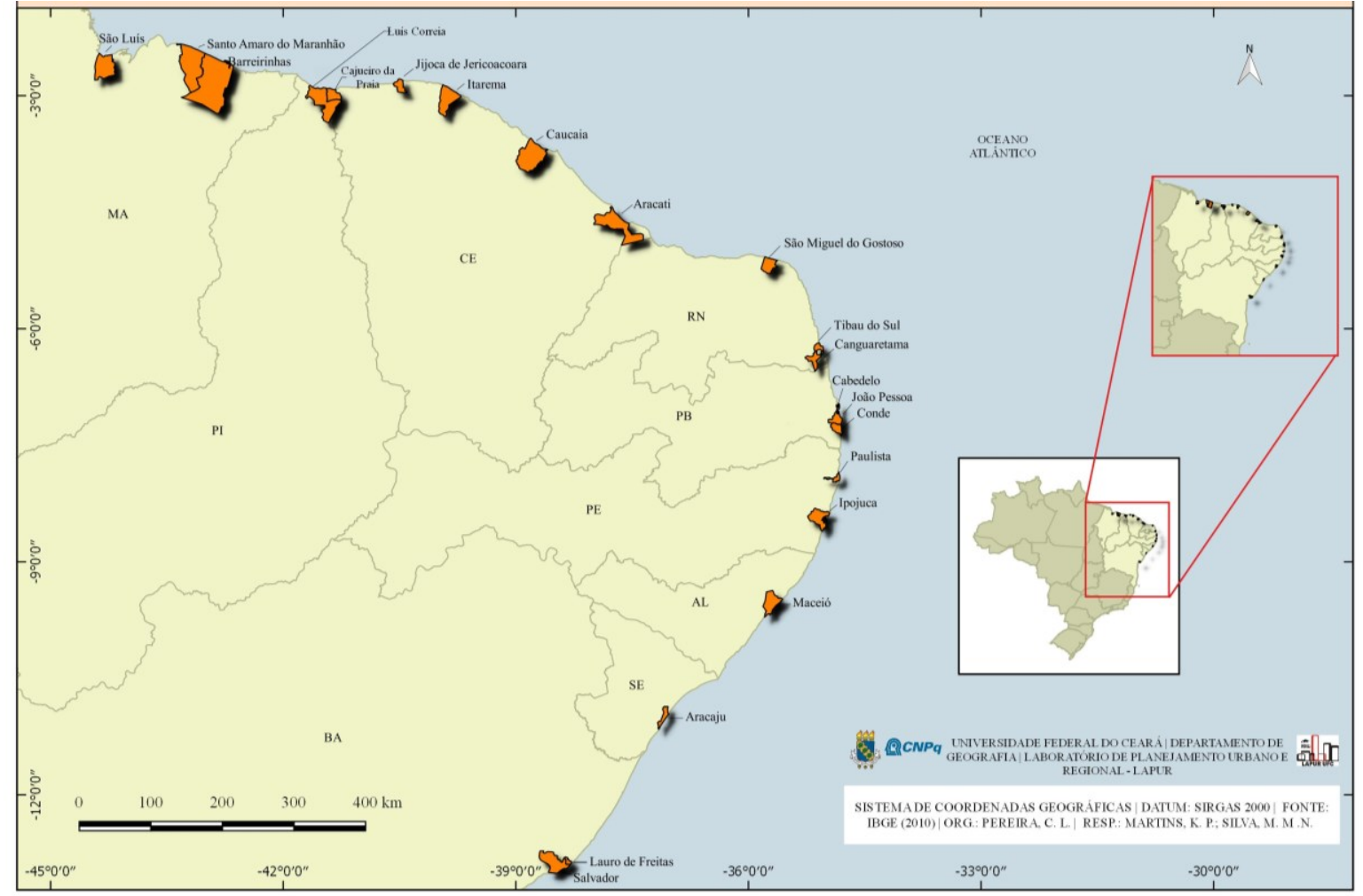

Fonte: Sitios eletrônicos especializados, trabalhos de campo e entrevistas. Org.: do autor.

Para o caso do litoral do estado do Ceara, Nordeste do Brasil, a disseminação da prática do kitesurfe constituiu rede de praias e de vilarejos anteriormente destinados a vilegiatura (PEREIRA, 2014). Estas localidades litorâneas tornam-se pontos de apoio ao desenvolvimento de percursos longos, velejados entre Cumbuco (Caucaia) a Jericoacora (Jijoca de Jericoacoara). Os praticantes percorrem mais de duas centenas de quilômetros com suas 
pranchas e "pipas", selecionando lugares para descanso e reorganização do roteiro (figura 6). Assim, utilizam-se de segundas residências, hotéis, pousadas e demais infraestruturas turísticas.

Figura 6. Litoral do Estado do Ceará e as indicações dos esportes náuticos.

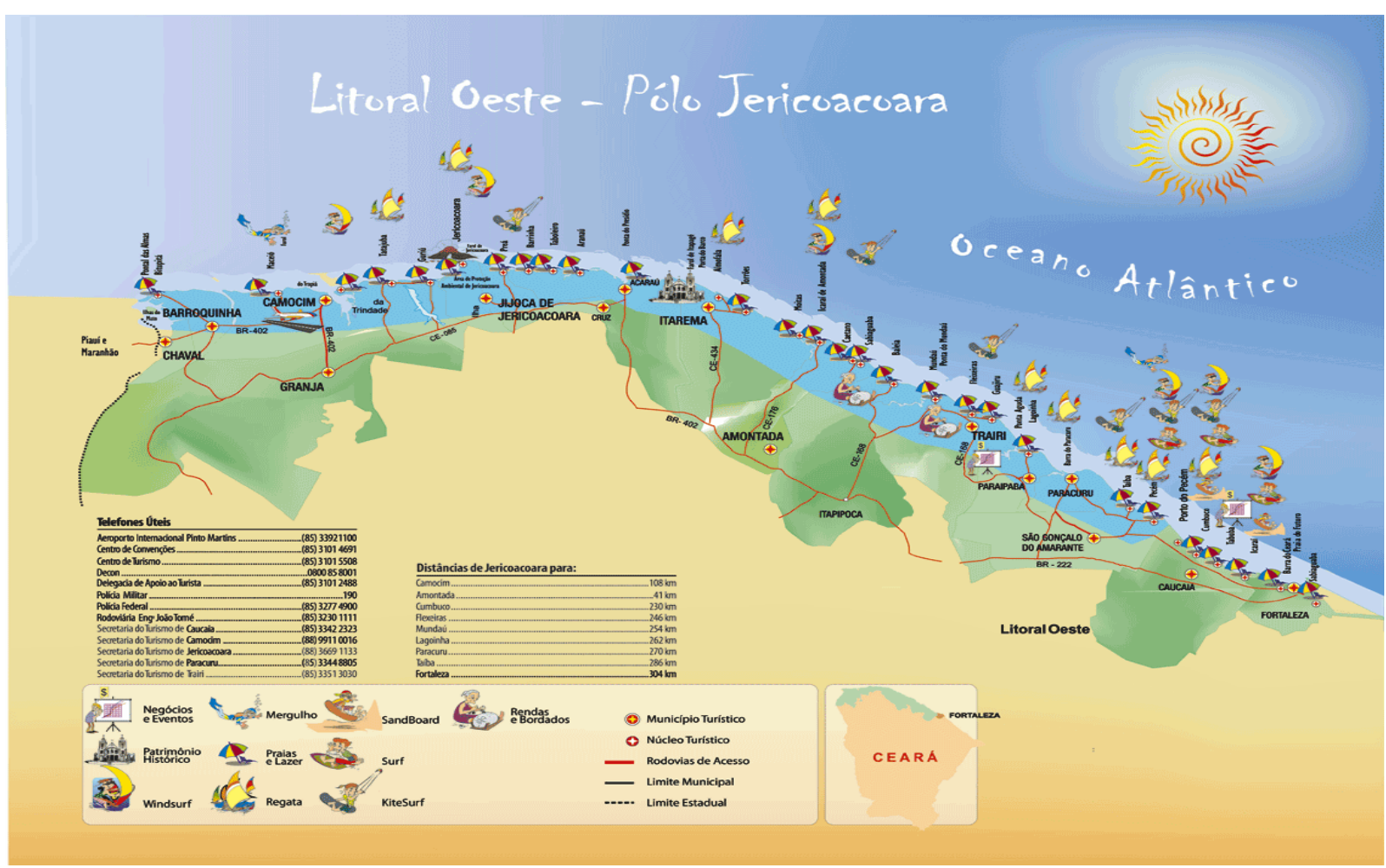

Fonte: Material promocional. Governo do Estado do Ceará. Brasil

Empreendimentos de lazer e hospedagem são criados e adaptados a fim de atender às demandas dos praticantes destes esportes de mar e vento. Em pesquisa qualitativa realizada por grupo de Urbanização Litorânea - LAPUR, foram consultados sites e revistas especializadas em kitesurfe, além da utilização da ferramenta Google Maps, com intenção de identificar a disponibilidade de pousadas e/ou hotéis, lojas, oficinas ou escolas de instrução voltadas para os velejadores.

O kitesurfe demanda infraestrutura relativamente mais qualificada em relação a outras práticas à beira-mar comuns ao litoral nordestino. Tratam-se 
de lojas e oficinas que propiciam reparos nos materiais utilizados na prática esportiva; escolas de instrução de aprendizes; como também, meios de hospedagem especificamente criados para tal prática (recolhimento do equipamento esportivo e serviços de transporte até locais propícios a prática). Há vários casos onde os proprietários dos empreendimentos são praticantes ou ex-praticantes, fato estes a possibilitar a criação de serviços especializados e atrair maior clientela. Com base nos dados do Ministério do Turismo, o quadro 2 lista a classificação turística dos municípios com maior incidência de praticantes de kitesurfe e, respectivamente, o número de empreendimentos preparados para atender os praticantes.

Quadro 2. Municípios nordestinos com maior incidência de praticantes de kitesurfe e suas respectivas categorizações turísticas, segundo o ministério do Turismo.

\begin{tabular}{|c|l|c|c|}
\hline ESTADO & \multicolumn{1}{|c|}{ CIDADE } & $\begin{array}{c}\text { Categorização } \\
\text { Turística }\end{array}$ & $\begin{array}{c}\text { Número de } \\
\text { Empreendimentos }\end{array}$ \\
\hline MA & Barreirinhas & C & 1 \\
\hline MA & São Luís & A & 1 \\
\hline MA & Santo Amaro do Maranhão & D & 0 \\
\hline PI & Cajueiro da Praia & D & 4 \\
\hline PI & Luis Correia & C & 2 \\
\hline CE & Caucaia & B & 7 \\
\hline CE & Itarema & D & 4 \\
\hline CE & Jijoca de Jericoacoara & B & 9 \\
\hline CE & Aracati & B & 1 \\
\hline RN & São Miguel do Gostoso & C & 1 \\
\hline RN & Tibau do Sul & B & 2 \\
\hline RN & Canguaretama & C & 1 \\
\hline PB & Cabedelo & C & 1 \\
\hline PB & João Pessoa & A & 1 \\
\hline PB & Conde & C & 0 \\
\hline PE & Ipojuca & A & 0 \\
\hline PE & Paulista & A & 1 \\
\hline SE & Aracajú & A & 0 \\
\hline AL & Maceio & A & 1 \\
\hline BA & Lauro de Freitas & C & 1 \\
\hline BA & Salvador & A & 3 \\
\hline
\end{tabular}

Fonte: MTur, 2015. Elaborado por Claudio Pereira.

Os esportes de natureza praticados a beira mar reconfiguram, sobretudo em virtude dos fluxos de esportistas amadores, tanto municipalidades 
reconhecidamente bem estruturadas turisticamente, como alcançam novas destinações em estados e municipalidades em estruturação. Desta forma, a disseminação de práticas marítimas como o kitesurfe tem duplo efeito espacial: I) incrementa o hall de atividades e atrativos nas costas (polos) consolidados e receptivos a outras práticas marítimas modernas, como Salvador (Costa dos Coqueiros) e Fortaleza (Costa SolPoente); e II) Insere vilarejos e novos balneários (Cajueiro da Praia no Piaui e Barreirinhas no Maranhão, por exemplo) a lógica de valorização dos espaços litorâneos, adicionando-os à rede de lugares urbanizados em virtude de práticas de lazer e dos fluxos de citadinos originários de aglomerações urbanas de outras regiões e nacionalidades.

\section{Considerações finais}

A variedade de esportes e lazeres criados e ou adaptados as paragens litorâneas demonstra processo de reinvenção contínuo da praia e do marítimo como produtos sociais. Produtos que retroalimentam práticas já massificadas, como a vilegiatura marítima e o turismo.

Os circuitos internacionais de esportes no mar e na praia expressam um modelo mundial e comercial de divulgação de lugares simbólicos e interligados em rede. Tais praias, espalhadas por todos os continentes, tornam-se ícones e arquétipos de lugares ideais para o desenvolvimento profissional e amador destes esportes/práticas. Nestes lugares, características naturais (geomorfologia e clima) associam-se as infraestruturas de apoio, transporte e estadia e perfazem as condições necessárias para a atração crescente de vacanciers e esportivas. Surf e kitesurfe são exemplos propulsores.

O litoral do Nordeste brasileiro integra essa rede, sobretudo, a atender os interesses de milhares de praticantes amadores. Onde outrora 
predominavam as "velas" brancas das jangadas dos pescadores artesanais, atualmente abundam "velas" coloridas dos kitesurfistas.

Merece destaque, no domínio teórico-conceitual, estabelecimento de diálogo com grupo de pesquisadores franceses a lidar com estudos associados às práticas de lazer e turísticas, principalmente as de cunho esportivo (AUDINET, GUIBERT, SEBILEAU (2017); GUIBERT e SLIMANI (2011); SEBILEAU (2017)). Culmina em procedimento analítico a envolver habitantes das cidades-sede, embriagados no exercício das práticas náuticas e aquáticas enfatizadas e, também, exercitando outras centradas nos mesmos princípios (futebol de praia, vôlei de praia, caminhada nos calçadões, bem como frequentação de festivais ligados ao temário do marítimo). Valida-se, assim, a tese de Duhamel (2018), da viabilidade dos espaços turísticos ao da existência de dinâmica relacionada aos lazeres e em relação à qual os pesquisadores devem se colocar para apreender a realidade contemporânea.

\section{Agradecimentos}

Estudo desenvolvido no bojo do Laboratório de Planejamento Urbano e Regional da Universidade Federal do Ceará e a contar com recursos do CNPq na modalidade de Bolsa Produtividade, INCT Observatório das Metrópoles, CAPES PGPSE Proc. 88887.123947/2016-00: Sistemas Ambientais costeiros e ocupação econômica do Nordeste; CAPES PRINT Proc. 88887.312019/2018-00: Integrated socio-environmental technologies and methods for territorial sustainability: alternatives for local communities in the context of climate change; e Programa CAPES/FUNCAP Proc. 88887.165948/2018-00: Apoio às Estratégias de Cooperação Científica do Programa de Pós-Graduação em Geografia - UFC. 


\section{Referências}

ALEDO, A. De la tierra al suelo: la transformación del paisaje y el Turismo Residencial. Arbor Ciencia, Pensamiento y Cultura. CLXXXIV, enero-febrero, p. 99$113,2008$.

ANDREU, H. G. Un acercaimento al concepto de Turismo Residencial. In: MAZÓN, T.; ALEDO, A. (Ed.). Turismo Residencial y cambio social. Alicante: Universidad de Alicante, 2005.

AUDINET, L.; GUIBERT, C.; SEBILEAU, A. Les "Sports de Nature". Paris: Édition du Croquant, 2017.

AUGUSTIN, J. P. L'attractivité plurielle d'une station océane : Lacanau-Océan dans le sud-ouest de la France, Téoros [En ligne], 26-2 | 2007, mis en ligne le 01 février 2011, consulté le 13 décembre 2012. URL : http://teoros.revues.org/830.

BLONDY, C. Pratiques de la plage em Polynésie française. M@ppemonde. 111 (2013.3). 1-17.

BOYER, M. L'invention du Tourisme. Paris Gallimard, 1996.

BOYER, M. Les villégiatures du XVIe au XXIe siècle. Caen: Éd. Management et Société, 2008.

CLAUDINO SALES, V. C. Os litorais cearenses. In: SILVA, J. B et al (orgs.). Ceará: um novo olhar geográfico. $2^{\mathrm{a}}$ ed. Fortaleza: Edições Demócrito Rocha, 2007. p. 231260.

CONTI, J. B. Geografia e tropicalidade. Revista da Casa de Geografia de Sobral, Sobral-CE, v. 12, n. 1, p. 47-58, 2010.

CORBIN, Alain. Le territoire du Vide. Paris: Aubier, 1988.

COSTA, M. C. L. Influências do Discurso Médico e do Higienismo no Ordenamento Urbano. Revista da ANPEGE, v. 9, p. 63-73, 2013. https://doi.org/10.5418/RA2013.0911.0006

DANTAS, E. W. C. Coastal Geography in Northeast Brazil: analyzing Maritimity in the Tropics. 1. ed. Berlin: Springer, 2016. https://doi.org/10.1007/978-3-319-30999-6

DELUMEAU, J. La peur em Occident, XVIème - XXIIIème siècles. Paris: Fayard, 1978.

DEMAJOROVIC, J. et. al. Complejos Turísticos Residenciales. Estudios y Perspectivas en Turismo, v. 20, p. 772-796, 2011.

DUHAMEL, Philippe. Géographie du Tourisme et des Loisirs. Paris: Armand Colin, 2018.

ELIAS, N. La civilisation des mœurs. Paris : Calmann-Levy, 1973.

FERNÁNDEZ MUNOZ, S.; TIMON, D. A. B. El Desarrollo Turístico Inmobiliario de la España Mediterránea y Insular frente a sus Referentes Internacionales (Florida y Costa Azul). Cuadernos de Turismo, n. 27, p. 373-402, 2011.

GUIBERT, C.; SLIMANI, H. Emplois sportifs et saisonnalités. L'économie des activités nautiques. Paris: L'Harmattan, 2011. 
GUIBERT, C. L'univers du surf et stratégies politiques en Aquitaine. Paris: L'Harmattan, 2006.

LERY, J. Histoire d'un voyage en terre du Brésil. Paris : Bibliothèque classique, 1994. LINHARES, P. Cidade de Água e Sal. Fortaleza: Fundação Demócrito Rocha, 1992.

MOURA, M. O. O clima urbano de Fortaleza sob nível do campo térmico. 2008. $281 \mathrm{f}$. Dissertação (Mestrado) - Curso de Geografia, Departamento de Geografia, Universidade Federal do Ceará, Fortaleza, 2008.

NIEVES, R. H. Tendencias del Turismo Residencial: el caso del mediterrâneo Españhol. El Periplo Sustentable, n. 14, p. 65-87, 2008. https://doi.org/10.21854/eps.v0i14.943

PEREIRA, A. Q. A Urbanização Vai à Praia. Fortaleza: Edições UFC, 2014.

RIEUCAU, J.; LAGEISTE, J. La plage, un territoire singulier: entre hétérotopie et antimonde. Géographie et Cultures, n. 67, p. 3-6, 2008. https://doi.org/10.4000/gc.995

SEBILEAU, A. Les Figures de l'Empiètement dans une commune du littoral. In: GUIBERT, Christophe; TAUNAY, Benjamin. Tourisme et Sciences Sociales. Paris: L'Harmattan, 2017.

SILVA, G. M. Orientação da linha de costa e dinâmica dos sistemas praia e duna: praia de Moçambique, Florianópolis, SC. 2006. 290 f. Tese (Doutorado) - Pósgraduação em Geociências, Universidade Federal do Rio Grande do Sul, Porto Alegre, 2006.

THEVET, A. Le Brésil d'André Thevet - les singularités de la France Antarctique (1557), Édition intégrale établie, présentée \& annotée par Frank Lestingant. Paris : Éditions Chadeigne, 1997.

TORRES BERNIER. E. El Turismo Residenciado y sus Efectos em los Destinos Turísticos. Estudios Turisticos, p. 45-70, 2013.

URBAIN, J.-D. Sur la Plage. Paris: Éditions Payot, 1996.

URRY, J. O olhar do turista: lazer e viagens nas sociedades contemporâneas. Tradução de Carlos Eugênio marcondes de Moura. São Paulo: Studio Nobel/SESC, 1996. 